\title{
Electromagnetic navigation bronchoscopy localization of lung nodules for thoracoscopic resection
}

\author{
Alessio Vincenzo Mariolo ${ }^{1}$, Thibault Vieira ${ }^{2}$, Jean-Baptiste Stern ${ }^{2}$, Loïc Perrot ${ }^{2}$, Raffaele Caliandro ${ }^{2}$, \\ Remi Escande ${ }^{1}$, Emmanuel Brian ${ }^{1}$, Madalina Grigoroiu ${ }^{1}$, Guillaume Boddaert ${ }^{1}$, Dominique Gossot ${ }^{1}$, \\ Agathe Seguin-Givelet ${ }^{1,3}$
}

${ }^{1}$ Thoracic Surgery Department, Institut du Thorax Curie-Montsouris-Institut Mutualiste Montsouris (IMM), Paris, France; ${ }^{2}$ Pulmonology Department, Institut du Thorax Curie-Montsouris-Institut Mutualiste Montsouris, Paris, France; ${ }^{3}$ Paris 13 University, Sorbonne Paris Cité, Faculty of Medicine SMBH, Bobigny, France

Contributions: (I) Conception and design: D Gossot, AV Mariolo, A Seguin-Givelet; (II) Administrative support: D Gossot, A Seguin-Givelet; (III) Provision of study materials or patients: D Gossot, A Seguin-Givelet, M Grigoroiu, E Brian, A Vincenzo Mariolo; (IV) Collection and assembly of data: AV Mariolo, A Seguin-Givelet; (V) Data analysis and interpretation: D Gossot, AV Mariolo, A Seguin-Givelet; (VI) Manuscript writing: All authors; (VII) Final approval of manuscript: All authors.

Correspondence to: Agathe Seguin-Givelet. Thoracic Department, IMM, 42 Bd Jourdan, F-75014 Paris, France. Email: agathe.seguin-givelet@imm.fr.

\begin{abstract}
Background: Thoracoscopic localization of small peripheral pulmonary nodules is a concern. Failure can lead to larger parenchymal resection or conversion to thoracotomy. This study evaluates our experience in preoperative electromagnetic navigation bronchoscopy-guided localization of small peripheral lung lesions.

Methods: From January 2017 to March 2020 clinical, radiographic, surgical, and pathological data of patients who underwent electromagnetic navigation bronchoscopy (ENB)-guided methylene blue pleural marking of highly suspected pulmonary lesions before a full thoracoscopic resection were evaluated. Localization was performed for solid or mixed subpleural nodules measuring $<10 \mathrm{~mm}$, solid nodules measuring $<20 \mathrm{~mm}$ located at more than $1 \mathrm{~cm}$ from the pleura and any pure ground glass opacity. Successful localization was defined as successful identification and thoracoscopic resection of target lesions.

Results: Forty-eight patients were included: 30 solid nodules (63\%), 12 pure GGO (25\%) and 6 mixed (13\%). The median largest diameter at CT-scan was $11 \mathrm{~mm}$ (IQR, 9-14 mm) while the median distance from the pleural surface was $12 \mathrm{~mm}$ (IQR, 6-16 mm). The median ENB length was $25 \mathrm{~min}$ (19-33 min). Localization procedure was successful in 45 cases (94\%). No procedural-related complications were reported. Conclusions: ENB is a safe and accurate preoperative procedure to localize small lung peripheral lesions. The high successful rate, the absence of related complications, the possibility of performing the procedure in the same operating room with a single general anesthesia, make ENB-guided dye marking an advantageous tool for thoracoscopic pulmonary resection.
\end{abstract}

Keywords: Electromagnetic navigation bronchoscopy (ENB); dye marking, peripheral lung nodule; thoracoscopy; early-stage lung cancer; video-assisted thoracoscopic surgery (VATS)

Submitted Feb 03, 2021. Accepted for publication Apr 09, 2021.

doi: $10.21037 /$ jtd-21-223

View this article at: https://dx.doi.org/10.21037/jtd-21-223

\section{Introduction}

The use of low-dose computed tomography scan (CTscan) for lung cancer screening programs (1) and the adoption of more sophisticated imaging tools in oncological follow-up (2) have drastically increased the number of indeterminate peripheral small pulmonary lesions suspected for non-small cell lung cancer (NSCLC) or lung metastases. Although non-surgical ablation treatments might be applied to some of these lesions in the future, surgical resection remains for the time being the gold-standard treatment, 
either by lobectomy, segmentectomy or wedge resection, depending on the clinical context and the pathological type. Unfortunately, in many cases, obtaining a preoperative diagnosis is an issue $(3,4)$ and surgical resection can be directly indicated (5). Nevertheless, intraoperative identification of small, underpleural-located solid or subsolid lesions [i.e., ground glass opacity (GGO)] may be challenging. This is even more true when the patient is operated using a closed chest technique, with no possibility of palpating the pulmonary parenchyma. This may lead the surgeon to perform larger parenchymal resections or convert to thoracotomy attempting bimanual palpation for successful resection (6). Various techniques for preoperative nodule localization have been proposed. The most common methods include percutaneous transthoracic CT-guided placement of a hook-wire, coils or radiotracer performed by interventional radiologist in the radiology department. Even if these methods are effective, they reported relatively high potential of pneumothorax, hematoma, bleeding or dislodgement of the tracer (7). Moreover, these techniques require to be performed with the coordination of multiple specialists and facilities, with delay and patient discomfort. The onset of electromagnetic navigation bronchoscopy (ENB) technology enabled transbronchial dye injection for pleural marking as alternative localization technique. The purpose of this study is to analyze our experience with preoperative ENB-guided methylene blue pleural marking to localize suspicious small peripheral lung nodule before a full thoracoscopic resection.

We present the following article in accordance with the STROBE reporting checklist (available at https://dx.doi. org/10.21037/jtd-21-223).

\section{Methods}

The study was conducted in accordance with the Declaration of Helsinki (as revised in 2013). The study was approved by the Ethical Committee for Clinical Research of the French Society for Thoracic and Cardiovascular Surgery (CERC-SFCTCV-2020-07-03---13-SEAG) and individual consent for this retrospective analysis was waived. A monocentric study was conducted retrospectively analyzing data from a prospectively collected database. Inclusion criteria included patients with nodules highly suspicious of primary pulmonary malignancy according to persistency or progression during follow-up imaging, or in case of lesions suspected for metastases in history of extrathoracic malignancy. For NSCLC, preoperative staging included chest CT and positron-emission tomography with fluorodeoxyglucose. All patients who were clinically suspected of mediastinal lymph node (LN) involvement (positive results on positron-emission tomography scan or with LNs larger than $1.5 \mathrm{~cm}$ on CT-scan) underwent endobronchial ultrasound-guided transbronchial needle aspiration or mediastinoscopy for staging.

ENB-dye marking was performed in case of pulmonary lesion presumed to be non-detectable during thoracoscopy according to the surgeon's evaluation. In particular: (I) solid or subsolid nodules smaller than $10 \mathrm{~mm}$ close to the pleural surface without pleural retraction at CT-scan; (II) solid nodules smaller than $20 \mathrm{~mm}$ located at more than $10 \mathrm{~mm}$ from pleural surface; (III) pure GGO lesions regardless the distance from the pleura. Patient demographics and nodule specific characteristics were collected. Preoperative data included localization, CT-scan characteristics, size and distance from the border of the lesion to the pleural surface based on measurements on lung window CT-scan. Data on operative characteristics, final pathological diagnosis and clinical outcome were collected. Primitive NSCLC were classified according to the 8th TNM classification.

\section{ENB planning, dye marking and surgical procedure}

\section{Preoperative planning and dye marking}

A CT-scan was obtained with pre-specified slice thickness of $1.25 \mathrm{~mm}$, overlap of $20 \%$ to $50 \%$, slice interval of $1 \mathrm{~mm}$, and standard convolution kernels. Preoperative mapping was performed using the SuperDimension ${ }^{\mathrm{TM}}$ Electromagnetic Navigation Bronchoscopy system (Medtronic, Plymouth, MN 55442, USA). The software reconstructed the virtual bronchoscopy view. After the identification of distinct anatomical registration points (i.e., carina and origin of lobar bronchus), the target lesion was outlined and a pathway to the target nodule was mapped. If a bronchus did not lead directly to the target, the software allowed the reconstruction of a virtual route selecting the best available exit point from the bronchial tree. All the ENB-guided localization procedures were performed immediately before surgery in the same surgical theater. Under general anesthesia with a singlelumen endo-tracheal tube, patient was placed in a supine position. A positive end-expiratory pressure (PEEP) higher than $10 \mathrm{cmH}_{2} \mathrm{O}$ was applied to mitigate end-expiratory alveolar collapse. A flexible fiberoptic bronchoscope with a working channel of $2.8 \mathrm{~mm}$ diameter was used to perform a regular bronchoscopy to clear the airway of secretions, thus a guide-sheath with an external diameter of $2.7 \mathrm{~mm}$ 

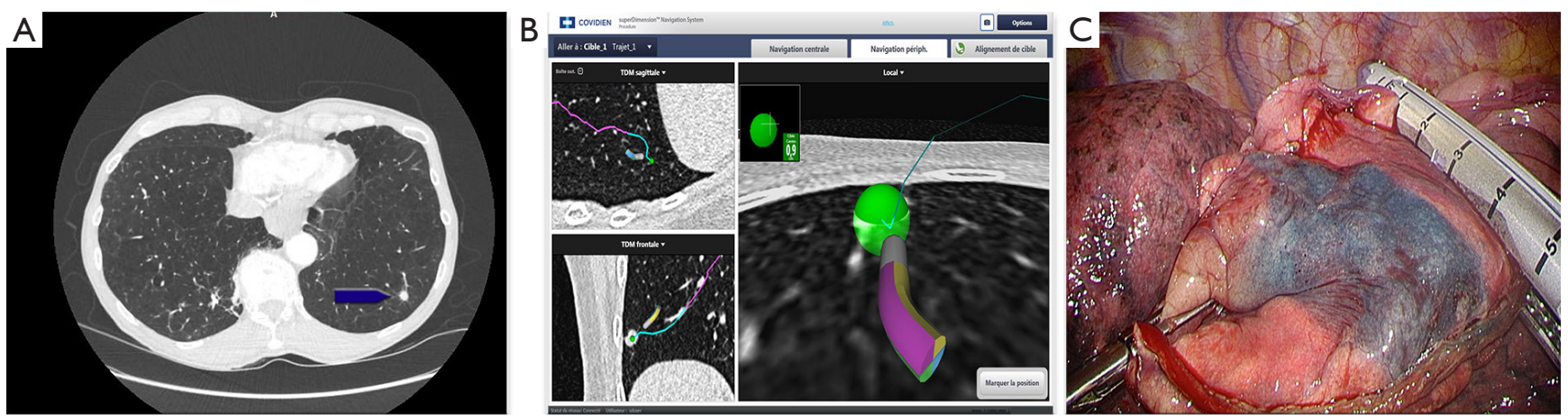

Figure 1 ENB-guided pleural dye marking for a small lung nodule's localization. (A) Lung CT-scan showing a deep located small target nodule (arrow); (B) navigation to the nodule up to the pleura; (C) thoracoscopic view of the methylene blue marking on the pleural surface. ENB, electromagnetic navigation bronchoscopy; CT, computed tomography.

were used to insert the locatable guide. This guide allowed for tracking position and orientation inside the bronchial tree. Two types of guide were available according to the folding angle of the tip: $90^{\circ}$ and $180^{\circ}$, which was chosen for the optimal theoretical angle to reach the target. In our experience a $90^{\circ}$-guide were mostly used for nodules located in the lower or middle lobe, while $180^{\circ}$-guide for targets in the upper lobe. A balancing inspection allowed the software to automatically register the airways to correlate the patient's anatomy with the CT-model. A virtual bronchoscopy image was then generated. Once the target was achieved, the catheter was driven forward to approximate the visceral pleural surface through the most direct route to the surface. The locatable guide was removed from the sheath and an endoscopic needle, preloaded with methylene blue, was used to inject a total of $1 \mathrm{~mL}$ of blue methylene followed by $20 \mathrm{~mL}$ of air pumped to ensure the total spill out of the operative channel. The needle and extended working catheter were then removed.

\section{Surgical procedure}

Once dye marking completed, the single tracheal tube was changed for a double-lumen tube. The patient was placed in a lateral decubitus position and a full thoracoscopic surgery was performed using a standardized technique, as previously described (8). A thoracoscopic examination of the visceral pleura was performed to spot the blue mark (Figure 1). In case of pulmonary lesion suspected for NSCLC, wedge resection was performed following by intraoperative examination. In case of confirmation of NSCLC, further anatomical segmentectomy or lobectomy was performed as well as a systematic hilar, intersegmental and mediastinal LN dissection. For anatomical segmentectomies, near- infrared imaging after systemic injection of indocyanine green (ICG) was used to delineate the intersegmental borders before parenchymal division (9).

\section{Results}

From January 2017 to March 2020 a total of 48 patients were included. The patient and nodule characteristics are presented in Table 1. There were 30 men (63\%) and 18 women $(38 \%)$ with a median age of 66 years (IQR, 59-70 years) and a median body mass index (BMI) of $23.6 \mathrm{~kg} / \mathrm{m}^{2}$ (IQR, 20.3-25.8 kg/m²). Thirty-eight patients (79\%) presented a highly suspected NSCLC and in 10 patients (21\%) ENB-guided was used to localize highly suspected metastatic lesions.

Pulmonary nodules were mostly located in the right lower lobe (19, 40\%). Preoperative CT-scan showed 30 solid nodules (63\%), 12 pure ground glass opacities (25\%) and 6 mixed lesions (13\%). The median largest diameter measured at preoperative CT-scan was $11 \mathrm{~mm}$ (IQR, 9-14 mm). The median distance between the pleural surface and the nearest peripheral margin of the lesion resulted $12 \mathrm{~mm}$ (IQR, 6-16 mm). None of the patients presented a bronchus leading directly to the target lesion (i.e., absence of a bronchus sign).

Final lung resection performed included 24 anatomical segmentectomies (50\%), 16 wedge resections (33\%) and 8 lobectomies (17\%). The median largest diameter of pulmonary nodules at pathological examination resulted $12 \mathrm{~mm}$ (IQR, 8-15 mm). Final pathological examination revealed 33 primary NSCLC (69\%), 11 extrathoracic metastases (23\%) and 4 benign nodules (8\%). According to the 8 th edition of TNM classification, 33 patients (93\%) 
Table 1 Population and preoperative data

\begin{tabular}{|c|c|}
\hline Variables & $\begin{array}{c}\mathrm{N}[\%] \text { or median } \\
{\left[25^{\text {th}}-75 \text { th quartiles }\right]}\end{array}$ \\
\hline \multicolumn{2}{|l|}{ Parameter } \\
\hline Total pulmonary lesions & $48[100]$ \\
\hline Male & 30 [63] \\
\hline Female & 18 [38] \\
\hline Age, years & $66[59-70]$ \\
\hline $\mathrm{BMI}, \mathrm{kg} / \mathrm{m}^{2}$ & 24 [20-26] \\
\hline \multicolumn{2}{|l|}{ Preoperative data } \\
\hline \multicolumn{2}{|l|}{ Nodule location } \\
\hline Right upper lobe & $6[13]$ \\
\hline Right middle lobe & $1[2]$ \\
\hline Right lower lobe & $19[40]$ \\
\hline Left upper lobe & 12 [25] \\
\hline Left lower lobe & $10[21]$ \\
\hline \multicolumn{2}{|l|}{ Nodule characteristics on CT-scan } \\
\hline Solid & 30 [63] \\
\hline Largest diameter, mm & $11[9-14]$ \\
\hline Distance to pleural surface, $\mathrm{mm}$ & $6[2-10]$ \\
\hline Mixed & $6[13]$ \\
\hline Largest diameter, mm & $11[9-13]$ \\
\hline Distance to pleural surface, $\mathrm{mm}$ & $6[2-10]$ \\
\hline GGO & 12 [25] \\
\hline Largest diameter, mm & $12[10-15]$ \\
\hline Distance to pleural surface, $\mathrm{mm}$ & $6[2-10]$ \\
\hline
\end{tabular}

BMI, body mass index; CT, computed tomography; GGO, ground glass opacity.

were early-stage diseases, while in two patients a N2 disease was upstaged. Final pathological characteristics, diagnosis and TNM classification for NSCLC are reported in Table 2. The median duration of ENB-guided localization procedure was $25 \mathrm{~min}$ (IQR, 19-33 $\mathrm{min}$ ). The blue-mark localization was effective in 45 patients $(94 \%)$. In one patient, methylene blue was found in the pleural cavity suggesting that during the procedure the needle passed through the visceral pleura displacing the dye into the chest cavity. In one other patient, the blue mark was not observable on the pleural surface during the thoracoscopic exploration and an anatomical segmentectomy was performed due to the high
Table 2 Final pathology and TNM classification for NSCLC

\begin{tabular}{|c|c|}
\hline Variables & $\begin{array}{c}\mathrm{N}[\%] \text { or median } \\
{\left[25^{\text {th}}-75 \text { th quartiles }\right]}\end{array}$ \\
\hline Median largest pathological diameter, mm & $12[8-15]$ \\
\hline \multicolumn{2}{|l|}{ Histology } \\
\hline Primary malignancy & 33 [69] \\
\hline Adenocarcinoma & 25 [52] \\
\hline Squamous cell carcinoma & $5[10]$ \\
\hline Carcinoid tumor & 1 [2] \\
\hline Small cell lung cancer & $1[2]$ \\
\hline Pulmonary MALT Iymphoma & $1[2]$ \\
\hline Secondary lesion & $11[23]$ \\
\hline Bowel and Colon & $7[15]$ \\
\hline Renal cancer & $1[2]$ \\
\hline Breast cancer & $1[2]$ \\
\hline Melanoma & $2[4]$ \\
\hline Benign & $4[8]$ \\
\hline Hamartochondroma & $2[4]$ \\
\hline Vascular malformation & 1 [2] \\
\hline Intraparenchymal lymph node & $1[2]$ \\
\hline \multicolumn{2}{|l|}{ TNM staging for primary lung cancer } \\
\hline pTisNO & $1[3]$ \\
\hline pT1aNo & 13 [39] \\
\hline pT1bNo & 15 [45] \\
\hline pT1cNO & $1[3]$ \\
\hline pT1aN2 & 1 [3] \\
\hline pT1bN2 & $1[3]$ \\
\hline урто* & $1[3]$ \\
\hline
\end{tabular}

*, for small cell lung cancer. NSCLC, non-small cell lung cancer; MALT, mucosa-associated lymphoid tissue-derived.

suspicion of NSCLC. Frozen section revealed an invasive adenocarcinoma. A fair amount of methylene blue was found within the lung parenchyma nearby the target nodule. In one other case, even if blue methylene was clearly visible on the pleural surface, the target nodule was not found in the specimen after wedge resection. Following conversion to thoracotomy the lesion was palpable just below the staple line. Operative characteristics of ENB-guided localization procedure are resumed in Table 3. 
Table 3 Operative characteristics

\begin{tabular}{lc}
\hline Variables & $\begin{array}{c}\text { N [\%] or median } \\
{\left[25^{\text {th }}-75 \text { th quartiles }\right]}\end{array}$ \\
\hline Parameter & \\
Total operative time (ENB + surgery), min & $197[90.5-240.7]$ \\
ENB duration, min & $25[19-33]$ \\
$\begin{array}{l}\text { Dye-mark visualization on the visceral } \\
\text { pleura }\end{array}$ & $46[96]$ \\
Type of final performed resection & \\
Wedge resection & $16[33]$ \\
Anatomical segmentectomy & $24[50]$ \\
Lobectomy & $8[17]$
\end{tabular}

ENB, electromagnetic navigation bronchoscopy.

There were no reported complications related to the ENB-guided localization procedure.

\section{Discussion}

Since the advent of low-dose CT-scan for lung cancer screening and oncological surveillance, the finding of small indeterminate lung nodules and GGO is increasing and minimally invasive surgical resection is more and more indicated for diagnostic and therapeutic intent (1). Nevertheless, localization of these small lesions is still a concern. Several preoperative localization techniques have been described mostly using percutaneous CT-guided placement of dyes, hooks, coils or radiotracers (10). These techniques are effective with a high successful rate and share the advantage of being widely available and reproducible even in non-expert departments. Nevertheless, drawbacks are not irrelevant with reported complication rate of pneumothorax and lung hemorrhage up to $39 \%$ and $22 \%$ of cases respectively (7). In case of wire placement, the risk of dislodgement is up to $13 \%$ (10) resulting higher when target nodules are located on the diaphragmatic or mediastinal surface of the lung due to the atelectasis of the parenchyma during single lung ventilation or following surgeon's manipulation. The injection of radiopaque markers, such as lipiodol (11), micro-coils (12) or cyanoacrylate (13), showed a lower rate of complications. Nevertheless, the localization of the tracer requires fluoroscopy with its attendant radiological risks for patient and operative team. Moreover, micro-coils tend to easily migrate and may lead to over-resection, while the effect of cyanoacrylate on lung tissue makes the pathologic study of frozen specimens for intraoperative diagnosis arduous because of the inability of the pathologist to cut through the area localized by the tracer. Radio-guided technique, using CT-guided injection of macroaggregates of technetium $99 \mathrm{~m}$ (14) or suspension of barium are also described (15). Nevertheless, these techniques are highly operator and facility dependent due to radiotracer positioning and the necessity of dedicated probes. Also, barium may provoke an inflammatory response that could hinder pathologic diagnosis. All the above-mentioned techniques share the awkward of being performed in the radiology department in a conventional two-stage workflow where localization precedes surgery that instead performed in the operating room of the surgical department. This requires the organization within multiple specialists and facilities, with potential waste of time, resources, delay in complication's management and discomfort for the patient. Some explorative studies have already evaluated the use of ENB to perform preoperative marking (16-23). In the current study ENB-guided pleural dye marking as preoperative localization of small, pulmonary, highly suspected malignant lesions result feasible. This technique provides several advantages. First of all, the localization procedure can be performed through the same operative session, by the same operator, in the same surgical theater thus avoiding delays and patient discomfort also allowing the surgeon to precisely determine where to place the marker according to the planned surgical approach. Patients are not exposed to the radiation required for imaging-guided procedures or intraoperative fluoroscopy and undergo a single general anesthesia. Most importantly, in our experience there were no procedurerelated complications such as bleeding or embolism and the procedure was accomplished within a limited additional time. In our experience the blue mark also facilitated the intersegmental plane division. Indeed, even if in our center a $3 \mathrm{D}-\mathrm{CT}$ reconstruction and modelization is used to accurately determinate the position of the lesion and ICG fluorescence is routinely performed for intersegmental plane delineation (24) methylene blue mark well defined the parenchymal area in which the nodule was located and could guide the stapling direction with the purpose of including all the marked parenchyma. This can reduce the possibility of stapling failure or inadequate security margins (25). We reported three cases of failure. In one case, we found the dispersion of the dye in the thoracic cavity, in one case the blue pleural mark was undetectable on the pleural surface and, in the last one, the target nodule was not included in the 
resected specimen localized by the dye. Since our technique has not been modified, we can assume that the failures were due to the unsuccessful achievement of the target lesion during the endobronchial navigation. A coherent explanation can be related to a constitutive technical issue known as CT-body divergence (26). Indeed, it exists a registration divergence between the CT-scan used for the preoperative planning and the anatomy of the patient once he is positioned on the operating table. This miscorrelation can affect the accuracy of the localization thus inducing surgeon to inject the dye while he is too far or too close to the target lesion. New advanced bronchoscopy systems with real-time three-dimensional imaging adjuncts probably will overcome divergence thus improving precision yield (27).

Several limitations affect this study. First, even if this study report one of the larger collections using ENBguided localization technique, the sample size is still small and include a highly-select group of patients. Second, we did not compare the blue methylene dye used in this study with other marker, coil or tracers, i.e., ICG, used in other endobronchial electromagnetic-guided localization techniques. Randomized study comparing ENBguided technique with other techniques for preoperative localization would be warranted in the future. Lastly, this report did not include cost effectiveness analysis that should be taken in account, principally from centers that does not routinely use the ENB technology in their department. In conclusion, our initial experience shows that ENB overcomes many of the disadvantages associated with other preoperative localization techniques, which have become indispensable in the era of small lung resection using closed chest surgery. Together with preoperative modelization and the use of advanced imaging technologies in the operating room, it is an additional tool in the development of a precise and accurate surgical technique.

\section{Acknowledgments}

Funding: None.

\section{Footnote}

Reporting Checklist: The authors have completed the STROBE reporting checklist. Available at https://dx.doi. org/10.21037/jtd-21-223

Data Sharing Statement: Available at https://dx.doi. org/10.21037/jtd-21-223
Conflicts of Interest: All authors have completed the ICMJE uniform disclosure form (available at https://dx.doi. org/10.21037/jtd-21-223). DG reports personal fees from Delacroix-Chevalier, outside the submitted work, and he serves as an unpaid editorial board member of fournal of Thoracic Disease from Apr 2020 to Mar 2022. ASG reports personal fees from Medtronic, personal fees from Astra Zeneca, outside the submitted work. The other authors have no conflicts of interest to declare.

Ethical Statement: The authors are accountable for all aspects of the work in ensuring that questions related to the accuracy or integrity of any part of the work are appropriately investigated and resolved. The study was conducted in accordance with the Declaration of Helsinki (as revised in 2013). The study was approved by the Ethical Committee for Clinical Research of the French Society for Thoracic and Cardiovascular Surgery (CERC-SFCTCV2020-07-03---13-SEAG) and individual consent for this retrospective analysis was waived.

Open Access Statement: This is an Open Access article distributed in accordance with the Creative Commons Attribution-NonCommercial-NoDerivs 4.0 International License (CC BY-NC-ND 4.0), which permits the noncommercial replication and distribution of the article with the strict proviso that no changes or edits are made and the original work is properly cited (including links to both the formal publication through the relevant DOI and the license). See: https://creativecommons.org/licenses/by-nc-nd/4.0/.

\section{References}

1. de Koning HJ, van der Aalst CM, de Jong PA, et al. Reduced Lung-Cancer Mortality with Volume CT Screening in a Randomized Trial. N Engl J Med 2020;382:503-13.

2. Hanamiya M, Aoki T, Yamashita Y, et al. Frequency and significance of pulmonary nodules on thin-section CT in patients with extrapulmonary malignant neoplasms. Eur J Radiol 2012;81:152-7.

3. Welborn SL, Ohori NP, Nason KS, et al. Percutaneous computed tomography-guided biopsy performed by thoracic surgeons in 955 patients: A paradigm shift in image-guided thoracic procedures. J Thorac Cardiovasc Surg 2019;157:1239-45.

4. Dhillon SS, Harris K. Bronchoscopy for the diagnosis of peripheral lung lesions. J Thorac Dis 2017;9:S1047-58.

5. Cao C, D'Amico T, Demmy T, et al. Less is more: a shift 
in the surgical approach to non-small-cell lung cancer.

Lancet Respir Med 2016;4:e11-2.

6. Cardillo G, Regal M, Sera F, et al. Videothoracoscopic management of the solitary pulmonary nodule: a single-institution study on 429 cases. Ann Thorac Surg 2003;75:1607-11; discussion 1611-2.

7. Park CH, Han K, Hur J, et al. Comparative Effectiveness and Safety of Preoperative Lung Localization for Pulmonary Nodules: A Systematic Review and Metaanalysis. Chest 2017;151:316-28.

8. Gossot D. Atlas of Endoscopic Major Pulmonary Resections. 2nd edition. Springer International Publishing, 2018.

9. Seguin-Givelet A, Grigoroiu M, Brian E, et al. Planning and marking for thoracoscopic anatomical segmentectomies. J Thorac Dis 2018;10:S1187-94.

10. Zaman M, Bilal H, Woo CY, et al. In patients undergoing video-assisted thoracoscopic surgery excision, what is the best way to locate a subcentimetre solitary pulmonary nodule in order to achieve successful excision? Interact Cardiovasc Thorac Surg 2012;15:266-72.

11. Watanabe K, Nomori H, Ohtsuka T, et al. Usefulness and complications of computed tomography-guided lipiodol marking for fluoroscopy-assisted thoracoscopic resection of small pulmonary nodules: experience with 174 nodules. J Thorac Cardiovasc Surg 2006;132:320-4.

12. Finley RJ, Mayo JR, Grant K, et al. Preoperative computed tomography-guided microcoil localization of small peripheral pulmonary nodules: a prospective randomized controlled trial. J Thorac Cardiovasc Surg 2015;149:26-31.

13. Tyng CJ, Nogueira VH, Bitencourt AG, et al. Computed tomographically guided injection of cyanoacrylate in association with preoperative radioguided occult lesion localization of ground-glass opacities. Ann Thorac Surg 2015;99:1838-40.

14. Galetta D, Bellomi M, Grana C, et al. Radio-Guided Localization and Resection of Small or Ill-Defined Pulmonary Lesions. Ann Thorac Surg 2015;100:1175-80.

15. Okumura T, Kondo H, Suzuki K, et al. Fluoroscopyassisted thoracoscopic surgery after computed tomography-guided bronchoscopic barium marking. Ann Thorac Surg 2001;71:439-42.

16. Krimsky WS, Minnich DJ, Cattaneo SM, et al. Thoracoscopic detection of occult indeterminate pulmonary nodules using bronchoscopic pleural dye marking. J Community Hosp Intern Med Perspect 2014. doi: 10.3402/jchimp.v4.23084.

17. Abbas A, Kadakia S, Ambur V, et al. Intraoperative electromagnetic navigational bronchoscopic localization of small, deep, or subsolid pulmonary nodules. J Thorac Cardiovasc Surg 2017;153:1581-90.

18. Awais O, Reidy MR, Mehta K, et al. Electromagnetic Navigation Bronchoscopy-Guided Dye Marking for Thoracoscopic Resection of Pulmonary Nodules. Ann Thorac Surg 2016;102:223-9.

19. Bolton WD, Cochran T, Ben-Or S, et al. Electromagnetic Navigational Bronchoscopy Reduces the Time Required for Localization and Resection of Lung Nodules. Innovations (Phila) 2017;12:333-7.

20. Luo K, Lin Y, Lin X, et al. Localization of peripheral pulmonary lesions to aid surgical resection: a novel approach for electromagnetic navigation bronchoscopic dye marking. Eur J Cardiothorac Surg 2017;52:516-21.

21. Marino KA, Sullivan JL, Weksler B. Electromagnetic Navigation Bronchoscopy for Identifying Lung Nodules for Thoracoscopic Resection. Ann Thorac Surg 2016;102:454-7.

22. Kuo SW, Tseng YF, Dai KY, et al. Electromagnetic Navigation Bronchoscopy Localization Versus Percutaneous CT-Guided Localization for Lung Resection via Video-Assisted Thoracoscopic Surgery: A PropensityMatched Study. J Clin Med 2019;8:379.

23. Bowling MR, Folch EE, Khandhar SJ, et al. Pleural dye marking of lung nodules by electromagnetic navigation bronchoscopy. Clin Respir J 2019;13:700-7.

24. Gossot D, Seguin-Givelet A. Anatomical variations and pitfalls to know during thoracoscopic segmentectomies. J Thorac Dis 2018;10:S1134-44.

25. Gossot D, Lutz JA, Grigoroiu M, et al. Unplanned Procedures During Thoracoscopic Segmentectomies. Ann Thorac Surg 2017;104:1710-7.

26. Makris D, Scherpereel A, Leroy S, et al. Electromagnetic navigation diagnostic bronchoscopy for small peripheral lung lesions. Eur Respir J 2007;29:1187-92.

27. Pritchett MA, Bhadra K, Calcutt M, et al. Virtual or reality: divergence between preprocedural computed tomography scans and lung anatomy during guided bronchoscopy. J Thorac Dis 2020;12:1595-611. Erratum in: J Thorac Dis. 2020 Aug;12(8):4593-4595. doi: 10.21037/jtd-2020-60.

Cite this article as: Mariolo AV, Vieira T, Stern JB, Perrot L, Caliandro R, Escande R, Brian E, Grigoroiu M, Boddaert G, Gossot $\mathrm{D}$, Seguin-Givelet A. Electromagnetic navigation bronchoscopy localization of lung nodules for thoracoscopic resection. J Thorac Dis 2021;13(7):4371-4377. doi: 10.21037/jtd-21-223 